\title{
A bathymetry and altimetry profile across the Southwest Indian Ridge crest at $31^{\circ} \mathrm{S}$ latitude
}

\author{
A.B. Watts ${ }^{1}$, J.R. Cochran ${ }^{1}$, P. Patriat ${ }^{2}$ and M. Doucoure ${ }^{2}$ \\ ' Lamont-Doherty Geological Observatory of Columbia University, Palisades, NY 10964 (U.S.A.) \\ 2 Institut Physique du Globe, 4 Place Jussieu, Paris Cedex 05 (France)
}

\begin{abstract}
During March 1983 the $\mathrm{M} / \mathrm{V}$ "Marion Dufresne" obtained a bathymetry profile along more than $1500 \mathrm{~km}$ of a SEASAT altimeter sub-track across the Southwest Indian Ridge crest at $31^{\circ} \mathrm{S}$ latitude. We have used these data to estimate the thermal and elastic thickness of the oceanic lithosphere in the vicinity of the ridge and to evaluate the performance of the SEASAT altimeter. The thermal thickness appears to be in the range $72-109 \mathrm{~km}$ while the elastic thickness is about $2-5 \mathrm{~km}$. There is a good correlation between the geoid calculated from the bathymetry and its compensation and the observed geoid derived from SEASAT data. The correlation is strongest for wavelengths greater than $45 \mathrm{~km}$ and poorest for shorter wavelengths. We attribute the poor resolution at short-wavelengths to instrument and oceanographic noise in the altimeter data combined with the reduced sensitivity of the geoid to bathymetric relief at very short wavelengths.
\end{abstract}

\section{Introduction}

With the advent of satellite radar altimetry it has become possible to accurately determine the shape of the mean sea-surface or geoid in oceanic regions. The SEASAT radar altimeter, launched in 1978, measured sea-surface heights to a precision of better than $10 \mathrm{~cm} \mathrm{[1].} \mathrm{These} \mathrm{data} \mathrm{have} \mathrm{signifi-}$ cantly improved our understanding of oceanographic variability [2]. The amplitude of oceanographic features does not generally exceed several tens of centimeters, however, while the marine geoid ranges in amplitude from a few meters to a few hundred meters. The major contribution to the marine geoid therefore is from density differences in the Earth's interior.

Surface-ship gravity measurements have proved one of the principal means of determining the structure of the Earth beneath the oceans. In the absence of noise, geoid and gravity data provide equivalent information regarding the shape, den- sity contrast and depth of a disturbing body. Previous studies [3] have shown that gravity data derived from surface-ship measurements provide the best information at short-wavelengths, while geoid data derived from satellite altimetry provide the best information at longer wavelengths. The actual range of wavelengths for which one representation is more advantageous than the other depends on the signal to noise ratio of the data.

Because of its precision, satellite altimeter data has provided useful constraints on the thermal and mechanical properties of oceanic lithosphere. Over symmetrically spreading mid-ocean ridges the geoid decreases from the ridge crest to the flank and typically, the geoid anomaly is in the range 5-10 m over distances of $1000-2000 \mathrm{~km}$. Cazenave et al. [4] have used geoid data to estimate the thermal thickness of the oceanic lithosphere, $H$, in the vicinity of the Southeast Indian Ridge and East Pacific Rise and they found thicknesses in the range $70-90 \mathrm{~km}$. The geoid over large fracture-zone 
offsets typically shows a step to 1-3 m, downward from the younger, shallower side to the older, deeper side. Detrick [5] and Sandwell and Schubert [6] have used geoid data to estimate the value of $H$ in the vicinity of the Mendocino fracture zone. They found thicknesses in the range of 100 to $>125 \mathrm{~km}$. Over mid-plate swells, the geoid increases by about 6-8 $\mathrm{m}$. Haxby and Turcotte [7] and Crough [8] have used geoid data to show that the depth of compensation in the region of the Bermuda, Cape Verde, Hawaii, and Cook-Austral swells is about $60 \mathrm{~km}$. This depth is significantly smaller than the expected value of $H$ based on thermal age in the region suggesting extensive reheating of the lithosphere in the vicinity of swells. Over seamount and oceanic island volcanic load:; the geoid typically shows a $5-10 \mathrm{~m}$ high flanked by 1-3 m lows. Watts [9] and Cazenave and Dominh [10] have shown that the elastic thickness of the oceanic lithosphere, $T_{e}$, is in the range $30-40 \mathrm{~km}$ in the vicinity of the southeastern end of the Hawaiian Ridge, which loaded relatively old lithosphere $(-80 \mathrm{~m} . \mathrm{y}$.), and about $15-23 \mathrm{~km}$ in the region of the northern end of the Louisville Ridge, which appears to have formed on relatively young lithosphere (25-45 m.y.).

One of the principal contributions to the marine geoid are density differences due to variations in the topography of the seafloor. As a result, satellite altimeter data have been used to predict bathymetry in unexplored regions [11-13]. The relationship between altimeter data and bathymetry varies, however, with wavelength [9]. At shortwavelengths, the geoid effect of bathymetry is obscured because of noise in the altimeter data while at long wavelengths it is reduced due to isostasy. The wavelength "band" for which there will be a strong correlation between altimetry and bathymetry therefore depends on the noise levels of the altimeter data and the tectonic setting of the bathymetric feature.

Dixon et al. [13] constructed filters to predict the bathymetry along two SEASAT sub-satellite tracks in the Central Pacific Ocean. To account for isostasy they used an inverted response function based on a flexure model with $T_{\mathrm{e}}$ in the range $8.2-17.8 \mathrm{~km}$. They showed that bathymetric prediction is sensitive to $T_{\mathrm{e}}$ and the density assumed for the seafloor. To compensate for noise in the altimeter data they chose a "cut-off" wavelength, $\lambda_{c}$, of $20 \mathrm{~km}$ assuming that at shorter wavelengths there is no correlation between seafloor topography and the geoid, while at longer wavelengths there is a strong correlation. The actual value of $\lambda_{c}$ depends, however, on the noise levels of the SEASAT data.

Brammer and Sailor [14] have studied SEASAT data noise levels by analyzing the coherence between pairs of repeat tracks along selected arcs in the Atlantic and Pacific Oceans. They showed that the coherence is high at wavelengths greater than about $70 \mathrm{~km}$, is low at wavelengths less than 30 $\mathrm{km}$, and falls off rapidly for intermediate wavelengths. We point out, however, that their analysis only refers to the ability of SEASAT to resolve a geoidal waveform. Thus, it does not reveal the shortest wavelength down to which seafloor topography can be expected to contribute to the marine geoid.

The purpose of this paper is to present the results of an analysis of bathymetry and altimetry data obtained across the Southwest Indian Ridge crest. The bathymetry data was acquired by a surface-ship along a SEASAT sub-satellite track. It therefore differs from most previous studies which are based on bathymetry constructed along a sub-satellite track by interpolation between contour intervals on maps. The data discussed in this paper is, we believe, the first high-angle altimetry and bathymetry profile of a mid-ocean ridge crest. We use this data set to (a) to estimate the thermal and mechanical properties of the oceanic lithosphere in the vicinity of the ridge crest, and (b) evaluate the sensitivity of SEASAT altimeter data to seafloor topography.

\section{Data}

We use in this study bathymetry data collected along a SEASAT altimeter sub-satellite crossing of the Southwest Indian mid-ocean ridge crest (Fig. 1).

The bathymetry data was collected during March 3-6, 1983 on a cruise of the $R / V$ "Marion Dufresne". Satellite navigation enabled the vessel 


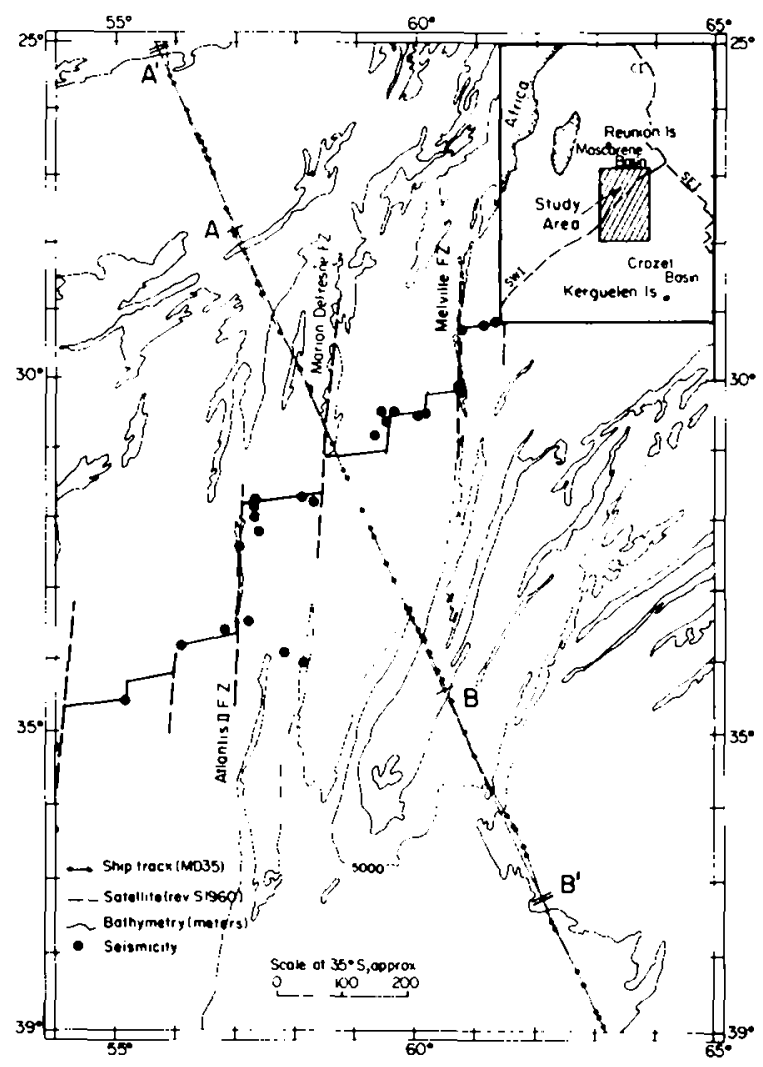

Fig. 1. Location map of the Southwest Indian Ridge. Bathymetry is based on the $1: 1,000,000$ GEBCO world bathymetry charts (1982). The solid heavy lines show the location of the mid-ocean ridge crest based on magnetic lineation and seismicity pattern studies [24]. The fine dashed line shows sub-satellite track S1960. The circles indicate satellite navigation positions along the MD35 surface-ship bathymetry track.

TABLE 1

SEASAT altimeter data used in this paper

\begin{tabular}{lll}
\hline Lamont ID No. & \multicolumn{2}{c}{ Time along track in study area } \\
\cline { 2 - 3 } & day & hours and minutes \\
\hline S0251 & 191 & $0159-0203$ \\
S0682 & 208 & $0313-0317$ \\
S5451 & 278 & $0811-0816$ \\
S3408 & 239 & $0527-0532$ \\
S1960 & 222 & $0419-0423$ \\
S3144 & 236 & $0520-0524$ \\
S1688 & 219 & $0412-0416$ \\
S2878 & 233 & $0515-0519$ \\
S1408 & 216 & $0405-0408$ \\
\hline
\end{tabular}

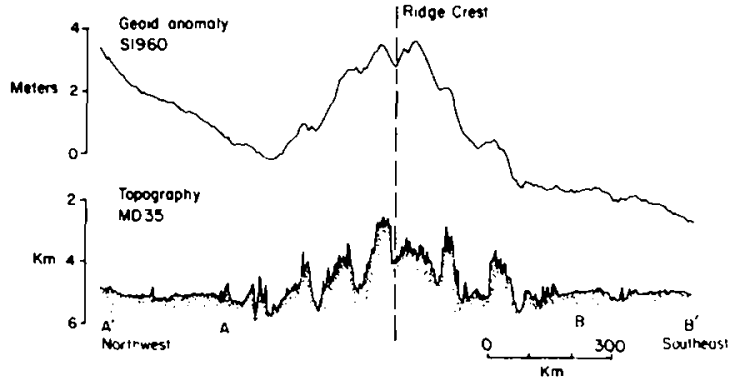

Fig. 2. Altimetry and bathymetry profile $A^{\prime} B^{\prime}$ (Fig. 1) across the Southwest Indian Ridge crest at $31.3^{\circ} \mathrm{S}$. The altimetry profile is based on SEASAT sub-satellite track S1960 (Table 1). A GEM10 reference field to degree and order $n=m=12$ was removed from the altimeter data prior to plotting. The bathymetry profile was obtained during March 1983 on a cruise of R/V "Marion Dufresne" (MD35).

to maintain a nearly constant course and stay within a few kilometers of the S1960 sub-satellite track (Fig. 1). The bathymetry data was acquired using a $12-\mathrm{kHz}$ precision depth recorder.

The SEASAT altimeter data was acquired during 0419 to 0423 hours on August 4, 1978. The data consist of 1 -second averages of the sea-surface height which have been corrected for instrument and atmospheric effects [15]. The SEASAT altimeter data covers a "swath width" of the sea surface of 2-12 km, depending on the sea state.

Fig. 2 summarizes the bathymetry and altimetry data along profile $A^{\prime} B^{\prime}$ (Fig. 1). The Southeast Indian Ridge is associated with a long-wavelength (wavelength $\lambda \sim 1100 \mathrm{~km}$ ) geoid high of about 4 m. A number of short-wavelength geoid highs correlate with topographic highs on the flanks of the ridge. The most prominent of these are 4 geoid highs of about $1 \mathrm{~m}$ amplitude and widths of 50-80 $\mathrm{km}$. The amplitude of the corresponding topographic highs is about $1200-1700 \mathrm{~m}$, indicating the ability of SEASAT data to resolve quite small features on the seafloor.

\section{Tectonic setting}

The SEASAT altimetry sub-track, S1960, and the coinciding R/V "Marion Dufresne" bathymetry profile, MD35, cross the Southwest Indian 
Ridge nearly normal to its general northeastsouthwest trend (Fig. 1). However, the direction of seafloor spreading at the Southwest Indian Ridge is approximately north-south $[16,17]$ and the ridge crest consists of relatively short east-west trending ridge segments connected by left-lateral transform faults $[18,19]$. Three major transform faults are located in the study area, the Atlantis II fracture zone at $57^{\circ} \mathrm{E}$, the Melville fracture zone at $60^{\circ} 30^{\prime} \mathrm{E}$ and an unnamed fracture zone at $58^{\circ} 30^{\prime} \mathrm{E}$ [18], each of which have troughs deep enough to allow transport of Antarctic Bottom Water north from the Crozet Basin into the Mascarene Basin [20]. Since bathymetry profile MD35 crosses the unnamed fracture zone near the ridge axis, we will refer to it in this paper as the Marion Dufresne fracture zone.

The Southwest Indian Ridge forms the southwest branch of a system of three ridges (Southwest, Central and Southeast Indian Ridges) connected at a RRR triple junction east of Reunion Island [21]. The spreading rate at the Southwest Indian Ridge is less than $1 \mathrm{~cm} / \mathrm{yr}[22,23]$ and for about 65 m.y. has been consistently slower than the two other ridges [24]. Usually, the evolution of a triple junction leads to a rapid increase of the length of the slower spreading ridge [25]. This is well seen at the axis of Southwest Indian Ridge which has been propagating to the northeast as the Central and Southeast Indian Ridges migrated away from Africa and Antarctica respectively. The rough bathymetry, numerous fracture zones and slow spreading rate makes it difficult to identify magnetic anomalies on isolated profiles of the ridge crest. However, Patriat [24] has verified a set of tentative identifications by reconstruction of each set of anomalies observed all along the ridge. According to this study, the oldest identified magnetic anomaly varies from anomaly 24 ( $\sim 53$ m.y. B.P.) in the northwest to anomaly $20(\sim 44 \mathrm{~m} . \mathrm{y}$. B.P.) in the southeast (Fig. 3).

There is an abrupt transition between the rough bathymetry generated at the Southeast Indian Ridge and the smooth bathymetry formed at the Central Indian and Southeast Indian Ridges that comprise the Madagascar and Crozet Basins. This transition is clearly visible on profile $A^{\prime} B^{\prime}$ and is shown in Fig. 1. The portion of profile $A^{\prime} B^{\prime}$

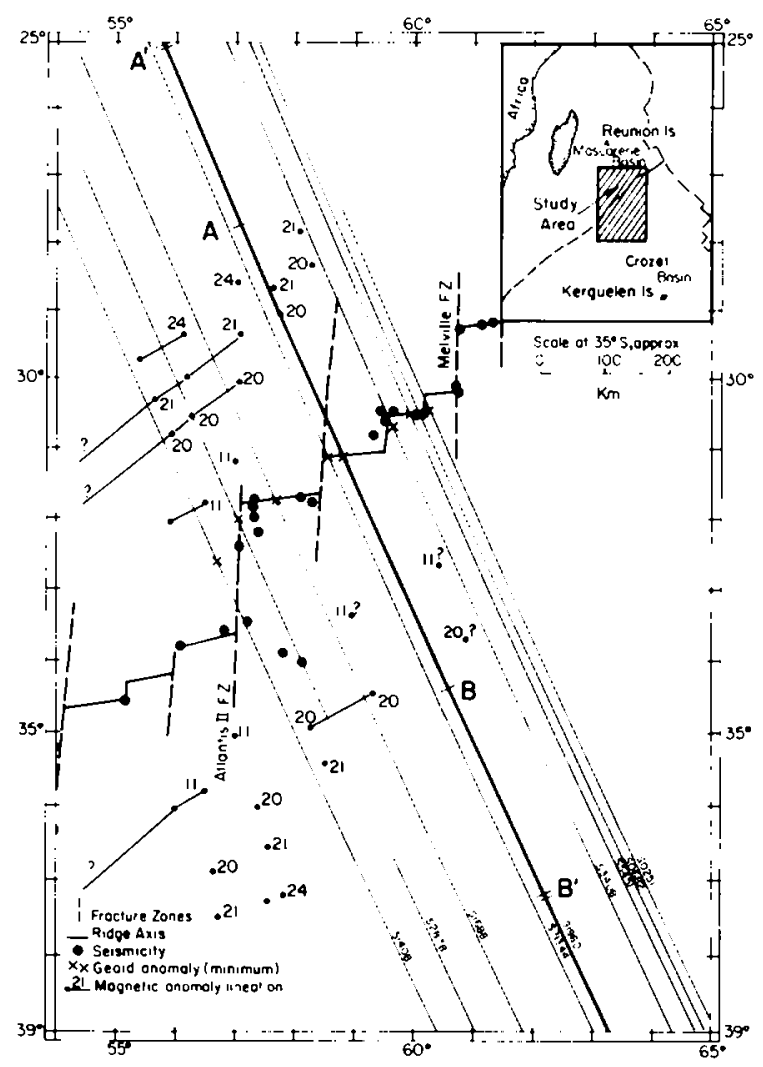

Fig. 3. Summary tectonic element map of the Southwest Indian Ridge crest. The heavy solid dots indicate magnetic anomaly identifications along ship's tracks based on Patriat [24]. The fine lines indicate sub-satellite tracks profiles in the study area. The heavy line indicates the location of the satellite sub-track S1960 which is nearly coincident with bathymetry profile MD35 (Fig. 1).

analyzed in this study (profile $A B$, Figs. 1 and 2) is located over the region of rough bathymetry and therefore only consists of crust generated at the Southwest Indian Ridge.

\section{Results}

The most prominent feature of SEASAT altimeter profile S1960 is a geoid high over the Southwest Indian Ridge with a width comparable to that of the ridge. This broad anomaly has been atrributed to the geoid effect of the ridge and its compensation [26]. Mid-ocean ridges are believed 
to be approximately in isostatic equilibrium; the topography of the ridge flanks being compensated by elevated temperatures throughout the lithosphere. Thus, the geoid high provides information on the thermal structure in the vicinity of a ridge.

There are two models currently in use that describe the thermal structure of the oceanic lithosphere; the half-space and cooling plate models. The half-space model assumes that the oceanic lithosphere can be treated as a cooling thermal boundary layer and predicts that the plate thickness and seafloor depth should increase linearly with the square root of age $[27,28]$. The cooling plate model, on the other hand, assumes that the oceanic lithosphere approaches some maximum thickness with age and predicts that the seafloor depth should also increase asymptotically to some maximum value $[29,30]$. This model requires that additional heat be added in some manner to the base of the lithosphere and that the equilibrium plate thickness is determined through establishment of a balance between the heat lost at the upper surface and that added to the bottom. The two models predict similar depths near the ridge crest, but diverge for older crust as the ridge begins to flatten out and approach its asymptotic depth.

Haxby and Turcotte [7] derived an expression for the geoid height, $\Delta h$, resulting from a thermally compensated mid-ocean ridge using the cooling half-space model. They showed that:

$\Delta h=-\frac{2 \pi G \rho_{\mathrm{m}} \alpha\left(T_{\mathrm{m}}-T_{0}\right) k}{g}\left[1+\frac{2 \rho_{\mathrm{m}} \alpha\left(T_{\mathrm{m}}-T_{0}\right)}{\left(\rho_{\mathrm{m}}-\rho_{\mathrm{w}}\right) \pi}\right] t$

where $G$ is the gravitational constant, $g$ is average gravity, $\alpha$ is the coefficient of thermal expansion, $k$ is the thermal diffusivity, $\left(T_{\mathrm{m}}-T_{0}\right)$ is the temperature difference across the lithosphere, $\rho_{m}$ and $\rho_{w}$ are the densities of the mantle and sea-water respectively, and $t$ is the age of the lithosphere. This expression predicts that the geoid height decreases linearly with age from a spreading center and Haxby [31] has used the variation in the slope of the geoid height-age relationship to determine information on the thermal parameters appropriate to different mid-ocean ridges.
Sandwell and Schubert [32] used gridded geoid heights based on GEOS-3 data and found that, in the Atlantic Ocean, the geoid height-age relationship flattened out markedly at an age of about 60-80 m.y. They used the Parsons and Sclater [30] expression for the thermal structure of the plate and the Ockendon and Turcotte [33] approximation for the geoid to derive a geoid-age relationship for the cooling plate and showed that:

$$
\begin{aligned}
\Delta h= & -\frac{2 \pi G H^{2}}{g}\left\{\left(\rho_{\mathrm{m}}-\rho_{\mathrm{w}}\right) \frac{w^{2}(t)}{2}+\alpha \rho_{\mathrm{m}}\left(T_{\mathrm{m}}-T_{0}\right)\right. \\
& \left.\times\left[\frac{1}{6}+\frac{2}{\pi^{2}} \sum_{n=1}^{\infty} \frac{(-1)^{n}}{n^{2}} \exp \left(\frac{n^{2} \pi^{2} k t}{H^{2}}\right)\right]\right\} \quad(2)
\end{aligned}
$$

where $H$ is the plate thickness and $w(t)$ is the non-dimensional subsidence given by:

$$
\begin{aligned}
w(t)= & \frac{\alpha \rho_{\mathrm{m}} T_{\mathrm{m}}}{2\left(\rho_{\mathrm{m}}-\rho_{\mathrm{w}}\right)} \\
& \times\left[1-\frac{8}{\pi^{2}} \sum_{n=1}^{\infty} \frac{\exp \left(\frac{-(2 n-1)^{2} \pi^{2} k t}{H^{2}}\right)}{(2 n-1)^{2}}\right]
\end{aligned}
$$

Sandwell and Schubert [32] showed, however, that substitution of parameters used by Parsons and Sclater [30] for the North Atlantic into equation (2) could not reproduce the observed flattening of the Atlantic geoid height-age relationship particularly well.

Cazenave et al. [4] examined the geoid anomaly across large fracture zone offsets in the Pacific ocean and concluded that the best fit to the data was for a cooling plate, rather than a half-space, model for the lithosphere. They found a plate thickness in the range of $70-90 \mathrm{~km}$, which is somewhat smaller than the value deduced by Parsons and Sclater [30].

The geoid anomaly high on profile $A^{\prime} B^{\prime}$ flattens abruptly about $300 \mathrm{~km}$ either side of the Southeast Indian Ocean Ridge crest (Fig. 1). A similar flattening is observed (Fig. 4) on adjacent altimeter tracks. Fig. 2 shows that the flattening occurs within the region of rough bathymetry and therefore is associated with the thermal structure of the 


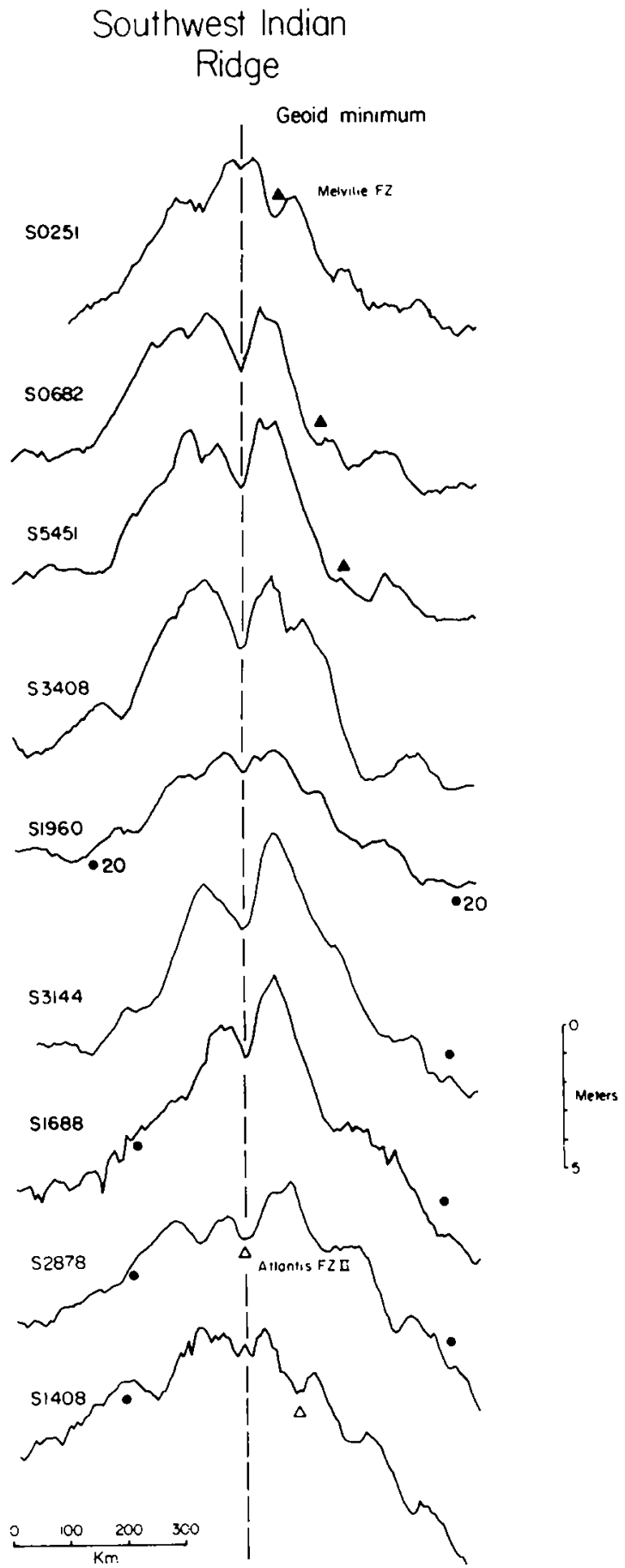

Fig. 4. Altimetry profiles S1408 to S0251 (Fig. 3; Table 1) of the southwest Indian Ridge crest. A GEM10 reference field to degree and order $n=m=12$ was removed from each profile prior to plotting. The ridge crest is associated with a prominent narrow geoid low of 1-2 $\mathrm{m}$ and a broad geoid high of 3-6 m.
Southwest Indian Ridges. The transition between rough and smooth bathymetry approximately corresponds to the location of magnetic anomaly 20 ( $\sim 44$ m.y. B.P.) southeast of the ridge crest and anomaly 24 ( $\sim 53$ m.y. B.P.) northwest of the ridge crest. Thus, the magnetic data (Fig. 3) suggest that the flattening is associated with oceanic crust younger than 44-53 m.y. This is younger than the age determined by Sandwell and Schubert [32] in the Atlantic, suggesting differences in thermal structure between the Atlantic and Southwest Indian ridges.

We compare in Fig. 5 calculated profiles for the geoid effect of a mid-ocean ridge to the observed

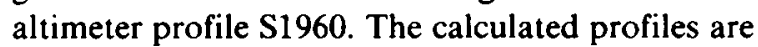
based on a cooling plate model with the thermal parameters summarized in Fig. 5. The age of the crust along the observed profile $A B$ (Fig. 1) was estimated using an average half-spreading rate of $0.6 \mathrm{~cm} / \mathrm{yr}$ resolved in the direction of the subsatellite tracks.

The best fit, in a least squares sense, between calculated and observed geoid profiles is for a thermal thickness, $H$, of $72 \mathrm{~km}$. However, as Fig. 4 shows the shape of the ridge geoid high changes along the ridge on either side of profile S1960. We found that the range of $H$ for the profiles in Fig. 4 is $72-107 \mathrm{~km}$ with a mean thickness of $88 \mathrm{~km}$ and standard deviation of $\pm 12 \mathrm{~km}$. Thus, the value of $H$ for $\mathrm{S} 1960$ is the lowest of all the values determined along the Southeast Indian Ridge.

There is an indication in Fig. 4 of a regional variation in $H$ along the strike of the Southwest Indian Ridge with thinner, hotter, lithosphere east of $58.5^{\circ} \mathrm{E}$ and thicker, colder, lithosphere west of $58.5^{\circ} \mathrm{E}$. The best fitting values of $H$ are less than $85 \mathrm{~km}$ for the eastern five profiles and greater than $96 \mathrm{~km}$ for the western four profiles. The consistency of our results can be seen from the fact that the best fitting values of $H$ for profiles S0251, S0682 and S5451, which cross the same segment of ridge crest within $35 \mathrm{~km}$ of each other (Fig. 1), are grouped in a $5-\mathrm{km}$ range $(81,76$ and $78 \mathrm{~km}$ respectively). However, it should be noted that the geoid anomaly highs on profiles S1960 and S3144, which are within $25 \mathrm{~km}$ of each other, have different shapes (Fig. 4) and imply quite different values of $H(72$ and $96 \mathrm{~km})$. 


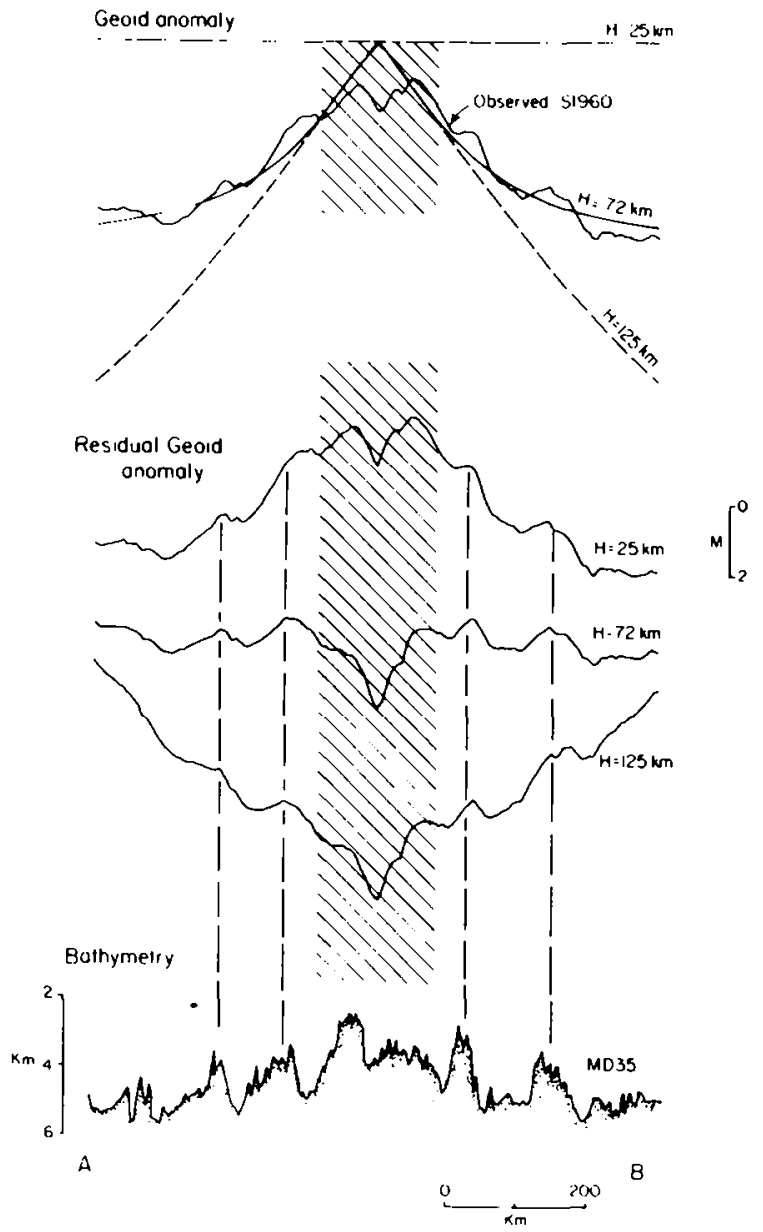

Fig. 5. Comparison of observed geoid anomaly profile $\$ 1960$ (Fig. 1) to calculated profiles based on a plate model for the cooling oceanic lithosphere. The calculated profiles are based on a mantle density of $\rho_{\mathrm{m}}=3.33 \mathrm{~g} / \mathrm{cm}^{3}$, a seawater density of $\rho_{w}=1.03 \mathrm{~g} / \mathrm{cm}^{3}$, coefficient of volume expansion $\alpha=3.2 \times 10^{-5}$ ${ }^{\circ} \mathrm{C}^{-1}$, mantle temperature $T_{\mathrm{m}}=1350^{\circ} \mathrm{C}$, thermal diffusivity $K=0.012 \mathrm{~cm}^{2} / \mathrm{s}$, and equilibrium thermal thicknesses of $H=$ 25.72 and $125 \mathrm{~km}$. The best overall fit to the observed geoid anomaly is for $H=72 \mathrm{~km}$. The residual geoid anomaly (observed-calculated) for $H=72 \mathrm{~km}$ shows prominent geoid highs of amplitude $50-120 \mathrm{~cm}$ and widths of $40-60 \mathrm{~km}$ associated with individual bathymetric highs on the ridge crest.

A prominent geoid low is associated with the mid-ocean ridge crest in each of the profiles in Fig. 4. This geoid low is not predicted by the thermal models and on bathymetry profile MD35 is not associated with any major bathymetric feature. However, a prominent axial rift is present in ad- jacent bathymetry profiles of the ridge [34]. Prominent isostatic gravity anomaly lows have been observed at a number of both fast- and slow-spreading mid-ocean ridge crests [35-37]. These anomalies are generally believed to be associated with axial processes at the ridge crest and the generation of new oceanic crust.

We show in Fig. 5 a "residual" geoid anomaly profile obtained by subtracting the observed SEASAT altimeter profile $\$ 1960$ from a calculated geoid profile based on the cooling plate model. The geoid profile with $H=72 \mathrm{~km}$ explains well the amplitude and wavelength of the prominent geoid high over the ridge crest leaving a residual geoid profile which is generally level across the ridge. The residual geoid profile is dominated by a low of more than $1 \mathrm{~m}$ amplitude located over the active portion of the ridge. Several short-wavelength geoid highs (amplitude generally less than 1 $m$ occur over the flanks of the ridge where they are associated with topographic highs.

At short wavelengths, the relationship between geoid and topography anomalies contains information on the nature of the isostatic mechanism and on the ability of SEASAT altimeter data to resolve topographic features on the seafloor. However, in order to isolate the short-wavelength features of the geoid it is necessary first to remove the long-wavelength anomaly associated with the thermal structure of the ridge. The difficulties with using the residual geoid anomaly profile in Fig. 5 are that (a) it is based on a preferred value of $H$ which has been shown to vary along strike of the ridge, and (b) thermal models do not adequately account for the geoid low in the vicinity of the ridge axis which previous studies [35-37] indicate is associated with axial processes at the ridge crest.

We compare in Fig. 6 the residual geoid anomaly to a filtered geoid anomaly obtained by filtering the observed geoid anomaly in Fig. 2 with a Gaussian filter. A filter half-width of $100 \mathrm{~km}(2 \sigma)$ was used. This filter reduces the amplitude of a $150 \mathrm{~km}$ wide Gaussian-shaped geoid anomaly, for example, by $\mathrm{e}^{-1}$ of its magnitude. Fig. 6 shows that Gaussian filtering removes the broad geoid anomaly associated with the ridge crest and successfully isolates the short-wavelength geoid anomalies that result from the topography of oce- 


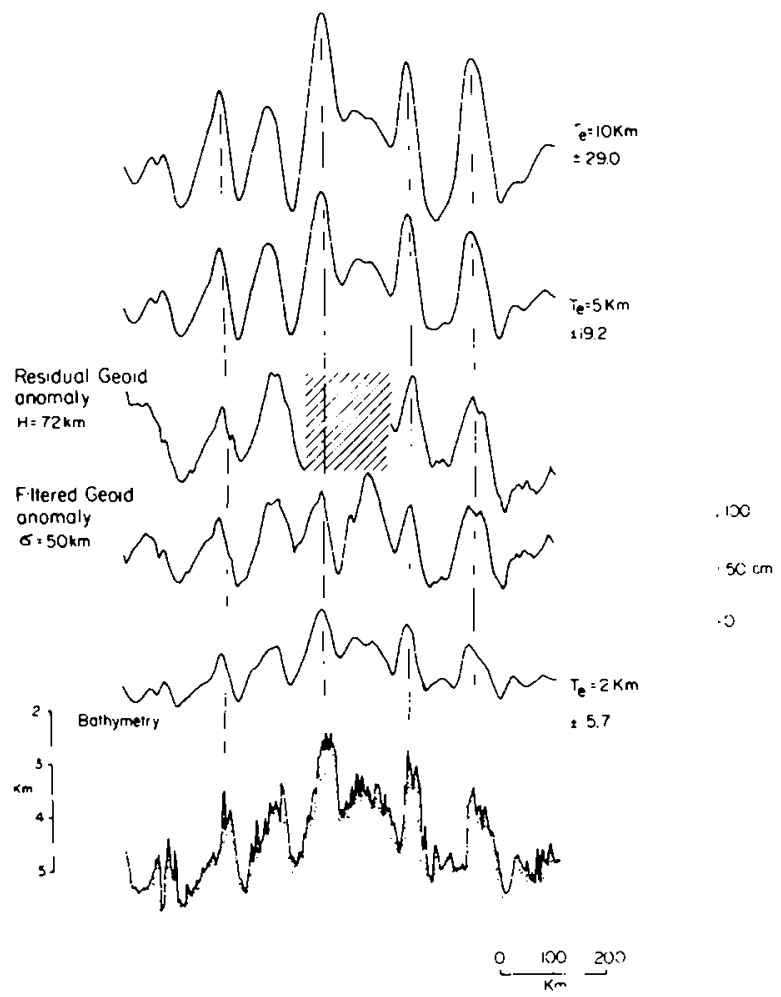

Fig. 6. Comparison of filtered and residual geoid anomaly profiles with calculated profiles based on the flexural model of isostasy. The filtered profile was obtained by high-pass Gaussian filtering altimeter profile S1960 with a filter half-width of $100 \mathrm{~km}$. The calculated profiles are based on an oceanic layer 2 density $\rho_{2}=2.6 \mathrm{~g} / \mathrm{cm}^{3}$, density of oceanic layer $3 \rho_{3}=2.9$ $\mathrm{g} / \mathrm{cm}^{3}$. density of mantle $\rho_{\mathrm{m}}=3.4 \mathrm{~g} / \mathrm{cm}^{3}$, thickness of the crust prior to nlexure $t_{c}=5 \mathrm{~km}$ elastic thickness of the oceanic lithosphere, $T_{e}=2,5$ and $10 \mathrm{~km}$, and assume two-dimensionality. A value of $T_{e}$ in the range $2-5 \mathrm{~km}$ appears to best fit the amplitude and wavelength of the filtered and residual profiles.

anic layer 2 and its compensation and other effects. There is close agreement between the shapes of filtered and residual geoid anomaly profiles over the ridge flank.

Fig. 6 compares the residual and filtered geoid anomaly profiles to calculated profiles based on a two-dimensional flexure model of isostasy. In this model individual bathymetric features on the seafloor are supported in part by the buoyancy of the underlying material and in part by the strength of the oceanic lithosphere. The calculated profiles are based on the parameters in Fig. 6 and different values of the effective elastic thickness, $T_{\mathrm{c}}$. The figure shows that the best fit between residual, filtered, and calculated profiles is for $T_{\mathrm{e}}$ in the range $2-5 \mathrm{~km}$.

One advantage of using the filtered profile rather than the residual profile is that it does not depend on the choice of a particular set of thermal model parameters. Furthermore, filtering removes at least part of the axial geoid low.

We illustrate the relationship between the filtered and best fitting filtered and calculated geoid profiles as a function of wavelength in Fig. 7. This figure shows the smoothed admittance, $Z(k)$, obtained by considering the filtered geoid as input and the calculated geoid as "output". $Z(k)$ is given by $G^{\prime}(k) / G(k)$ where $G^{\prime}(k)$ is the Fourier transform of the filtered geoid, $G(k)$ is the Fourier transform of the calculated geoid and $k$ is the wavenumber $(2 \pi / \lambda)$. Fig. 7 shows that there is a good correlation between filtered and calculated geoid at long wavelengths $\left(Z(k) \rightarrow 1, \log _{10} Z(k)\right.$ $\rightarrow 0)$ and a poor correlation at short wavelengths. The critical wavelength, $\lambda_{c}$, defining the transition from a strong to a poor correlation, is approximately $45 \mathrm{~km}$. We attribute the strong correlation for $\lambda>45 \mathrm{~km}$ to the ability of the SEASAT data to resolve the geoid effect of bathymetric features

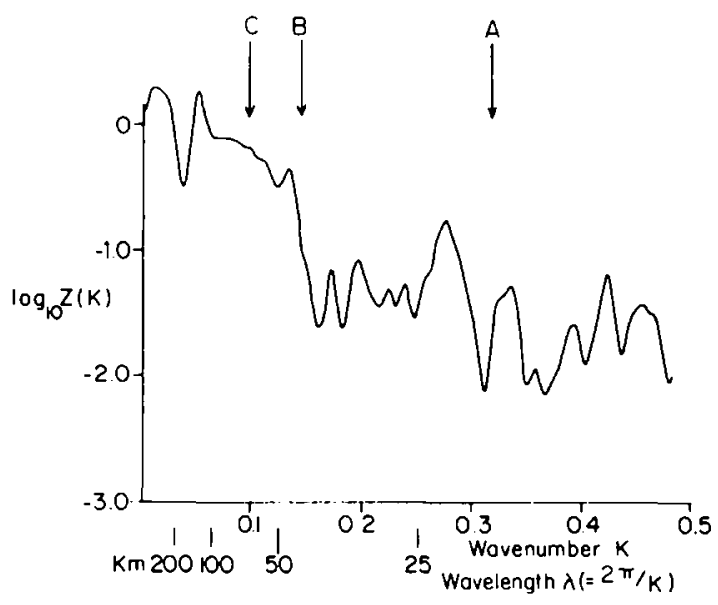

Fig. 7. $\log _{10} Z(k)$ plotted against $k$. The plot shows the relationship between the filtered and calculated profile $\left(T_{c}=5\right.$ $\mathrm{km})$ as a function of wavelength. At long wavelengths $(0.6<k$ $<0.15)$ there is a strong correlation between the filtered and calculated profiles while at short wavelengths $(k>0.14)$ there is a poor correlation. The arrows labeled $A, B$ and $C$ correspond to wavelengths of 20,45 and $70 \mathrm{~km}$ respectively. 
wider than about $22.5 \mathrm{~km}$. The poor correlation for $\lambda<45 \mathrm{~km}$ indicates that SEASAT is unable to resolve the geoid effect of narrower features across the Southwest Indian Ridge, due probably to instrument and oceanographic "noise".

These results suggest that $\lambda_{c}$ is an important parameter to define, especially if altimeter data is to be used to predict bathymetry in unsurveyed regions. For example, Dixon et al. [12] have used theoretical isostatic response functions to predict bathymetry from SEASAT data over the Central Pacific Ocean. They used an inverted admittance function, $Z^{-1}(k)$, to predict bathymetry for different values of $T_{\mathrm{c}}$. To compensate for the low signal to noise ratio at short wavelengths Dixon et al. [12] set the terms in $Z^{-1}(k)$ to zero for $\lambda \leqslant 20$ $\mathrm{km}$, equivalent to assigning $\lambda_{\mathrm{c}}=20 \mathrm{~km}$.

We have used the admittance technique [38] to predict bathymetry directly from altimeter data over the Southwest Indian Ridge. Fig. 8 shows predicted bathymetry profiles based on $T_{\mathrm{e}}=5 \mathrm{~km}$, the crustal parameters in Fig. 5, and values of $\lambda_{\mathrm{c}}$ of 20,45 and $70 \mathrm{~km}$. Fig. 7 indicates that for $\lambda<45 \mathrm{~km}$ there is a significant "noise" component in the altimeter data but for $\lambda>45 \mathrm{~km}$ this component is reduced. Thus, by selecting $\lambda_{\mathrm{c}}=20$ $\mathrm{km}$ (lowermost profile in Fig. 8) the noise is only partially removed and this leads to spurious bathymetry. $\lambda_{c}=70 \mathrm{~km}$, on the other hand, implies that too much of the short-wavelength components of the altimeter data is noise so only the broadest features of the bathymetry are predicted. A value of $\lambda_{c}=45 \mathrm{~km}$ appears to provide the best overall fit to the observed bathymetry profile on this crossing of the Southwest Indian Ridge.

It is not implied by the results in Fig. 8 that a value of $\lambda_{c}=45 \mathrm{~km}$ should necessarily be applicable to altimeter data over other oceanic regions. For example, the results in Fig. 8 differ from those of Dixon et al. [12]. These authors imply that $\lambda_{\mathrm{c}}=20 \mathrm{~km}$ satisfactorily predicts bathymetry data over the Musician Seamounts in the Central Pacific Ocean. Dixon et al. [12], however, pre-filtered the altimeter data using a 5-point $(18 \mathrm{~km})$ running mean. Fig. 9 shows that pre-filtering of altimeter data over the Southwest Indian Ridge, using the same technique as Dixon et al. [12], satisfactorily predicts bathymetry over the ridge. The Muscian

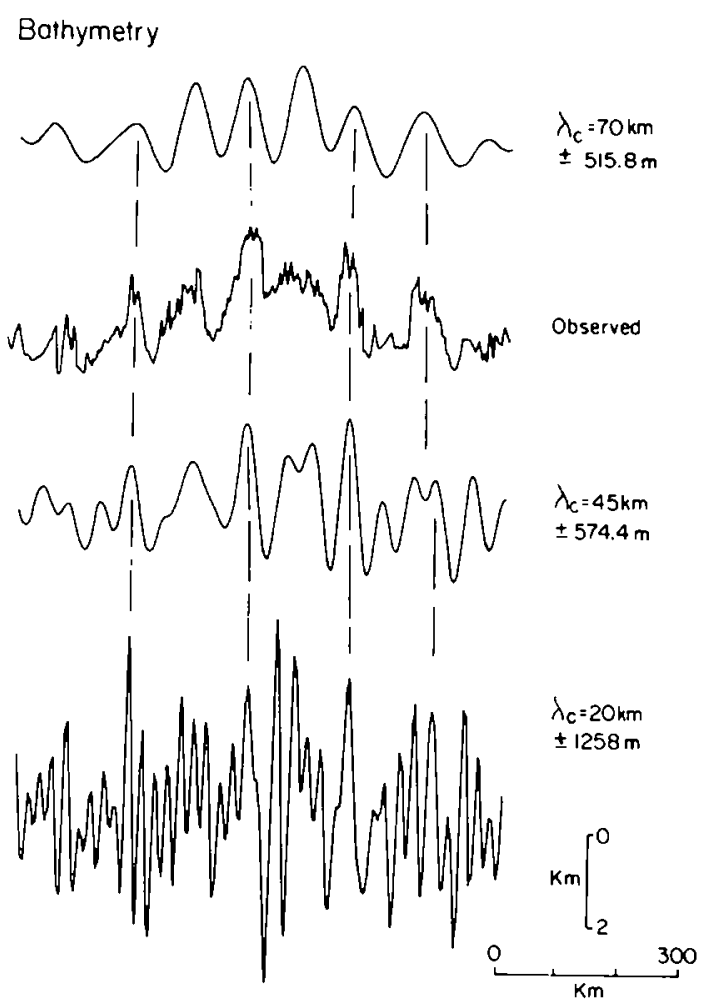

Fig. 8. Predicted bathymetry profiles obtained using filtered altimetry profile $\mathrm{S} 1960$ as an input to a filter derived from an inverted admittance function, $Z^{-1}(k) . T_{e}=5 \mathrm{~km}$ and other parameters are as in Fig. 6. The inverted admittance function has been shaped so that $Z^{-1}(k)=0$ for $k=0$ and $k>k_{\mathrm{c}}$. $k_{\mathrm{c}}=2 \pi / \lambda_{\mathrm{c}}$. The predicted bathymetry profiles are based on $\lambda_{\mathrm{c}}=20,45$ and $70 \mathrm{~km}$. The number to the right of each profile is the RMS difference (meters) between observed and calculated bathymetry.

Seamounts, like the topography of the Southwest Indian Ridge were generated at or near a mid-ocean ridge crest and apparently are associated with similar values of $T_{e}[12,38]$. Thus, a value of $\lambda_{\mathrm{c}}=45 \mathrm{~km}$ (with no pre-filtering) may be a suitable parameter to use generally for bathymetric prediction, at least in the vicinity of ridge crestgenerated features.

We point out, however, that poor track spacing, uncertainties in $T_{e}$, variations in pre-flexed crustal structure, and uncertainties in dimensionality combine to make bathymetric prediction from altimeter data difficult. This paper has shown that $\lambda_{c}$ is an additional factor limiting bathymetric predic- 


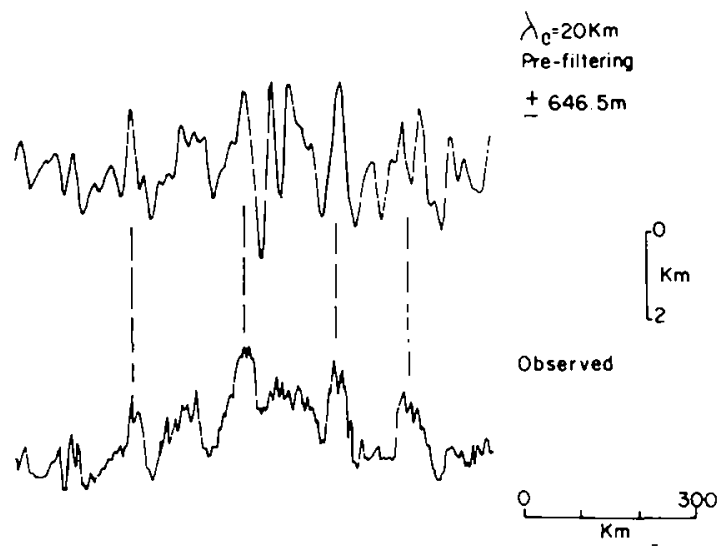

Fig. 9. Predicted bathymetry profile based on $\lambda_{c}=20 \mathrm{~km}$ compared to the observed bathymetry. The predicted profile was determined in the same way as for the profiles in Fig. 8 except that a 5-point $(18 \mathrm{~km})$ running mean was applied to the altimeter data prior to the prediction.

tion, probably due to instrument and oceanographic "noise". It is unfortunate, however, that we still do not know how the separate effects of instrument and oceanographic "noise" contribute to the marine geoid as a function of wavelength.

\section{Conclusions}

(1) The Southwest Indian Ridge is associated with a broad $(\lambda \sim 1100 \mathrm{~km})$ geoid high of $4 \mathrm{~m}$ superimposed on which are several narrow $(\lambda \sim$ $100-160 \mathrm{~km}$ ) geoid highs and lows of about $1 \mathrm{~m}$.

(2) The broad geoid high can be explained by a cooling plate model for the oceanic lithosphere. The best fitting thermal thickness of the lithosphere, $H$, is in the range $72-109 \mathrm{~km}$.

(3) The narrow geoid highs and lows can be explained by a two-dimensional flexure model for the isostatic compensation of seafloor topography. The best fitting elastic thickness of the lithosphere, $T_{e}$, is in the range $2-5 \mathrm{~km}$.

(4) There is a large amplitude geoid low centered over the crest of the ridge which cannot be fit by the thermal-mechanical models.

(5) The contribution to the SEASAT geoid of topography of the oceanic crustal layer varies as a function of wavelength. At long wavelengths $(\lambda>$
$45 \mathrm{~km}$ ) there is a strong contribution but at short wavelengths $(\lambda<45 \mathrm{~km})$ there is a small contribution.

(6) The principal factor limiting the ability of SEASAT altimeter data to resolve the geoidal effect of small features in the topography of the seafloor appears to be instrument and oceanic noise.

\section{Acknowledgements}

The bathymetry data used in this study was gathered as part of the Mission de la Recherche du Territoire des Terres Australes et Antarctiques Français. We thank A. Cazenave (Toulouse) for her encouragement and F. Frohlich (Paris) who was Chief Scientist of the MD35 cruise. This work was a result of a visit by the senior author (A.B.W.) to the Institut Physique de Globe de Paris. He is grateful to V. Courtillot and J.F. Minster for their hospitality during this visit. This work has been supported by the CNRS (France) and Office of Naval Research (U.S.A.). Lamont-Doherty Geological Observatory Contribution number 3782.

\section{References}

1 D.B. Lame and G.H. Born, SEASAT measurement system evaluation: achievements and limitations, J. Geophys. Res. 87, 3175-3178, 1982.

2 R.E. Cheney, J.G. Marsh and B.D. Beckley, Global mesoscale variability from collinear tracks of SEASAT altimeter data, J. Geophys. Res. 88, 4343-4354, 1983.

$3 \mathrm{M}$. Chapman and M. Talwani, Comparison of gravimetric geoids with Geos 3 altimetric geoid, J. Geophys. Res. 84, 3803-3816, 1979.

4 A. Cazenave, B. Lago and K. Dominh. Thermal parameters of the oceanic lithosphere estimated from geoid height data, J. Geophys. Res. 88, 1105-1118, 1983.

5 R.S. Detrick, An analysis of geoid anomalies across the Mendocino Fracture Zone: implications for thermal models of the lithosphere, J. Geophys. Res. 86, 11751-11762, 1981.

6 D.T. Sandwell and G. Schubert, Geoid height-age relation from SEASAT altimeter profiles across the Mendocino Fracture Zone, J. Geophys. Res. 87, 3949-3958, 1982.

7 W.F. Haxby and D.L. Turcotte, On isostatic geoid anomalies, J. Geophys. Res. 83, 5473-5478, 1978.

8 S.T. Crough, Geoid anomalies across fracture zones and the thickness of the lithosphere, Earth Planet. Sci. Lett. 44, 224-230, 1979. 
9 A.B. Watts, On geoid heights derived from GEOS-3 altimeter data along the Hawaiian-Emperor seamount chain. J. Geophys. Res. 84, 3817-3826, 1979.

$10 \mathrm{~A}$. Cazenave and K. Dominh. Geoid anomalies over the Louisville ridge (South Pacific), J. Geophys. Res., in press.

11 K. Lambeck and R. Coleman, A search for seamounts in the southern Cook and Austral region, Geophys. Res. Lett. 9. 389-392, 1982.

12 T.H. Dixon, M.E. Parke, Bathymetry estimates in the southern oceans from SEASAT altimetry, Nature 304 , 406-411, 1983.

13 T.H. Dixon, M. Naraghi, M.K. McNutt, S.M. Smith, Bathymetric prediction from SEASAT altimeter data, J. Geophys. Res. 88, 1563-1571, 1983.

14 R.F. Brammer and R.V. Sailor, Preliminary estimates of the resolution capability of the Seasat Radar Altimetry, Geophys. Res. Lett. 7, 193-196, 1980.

15 J. Lorell, M.E. Parke and J.F. Scott, Geophysical Data Record (GDR) Users Handbook, 90 pp., Jet Propulsion Laboratory, Pasadena, Calif., 1980.

16 I.O. Norton, The present relative motion between Africa and Antarctica, Earth Planet. Sci. Lett. 33. 219-230, 1976.

17 H.W. Bergh, and I.O. Norton, Prince Edward fracture zone and the evolution of the Mozambique Ridge. J. Geophys. Res. 81, 5221-5239, 1976.

18 J.G. Sclater, R.L. Fisher, P. Patriat, C: Tapscott and B. Parsons, Eocene to recent development of the Southwest Indian Ridge, a consequence of the evolution of the Indian Ocean Triple Junction, Geophys. J. R. Astron. Soc. 64, 587-604, 1981.

19 R.L. Fisher and J.G. Sclater, Tectonic evolution of the Southwest Indian Ocean since the Mid-Cretaceous: plate motions and stability of the pole of Antarctica/Africa for at least 80 m.y., Geophys. J. R. Astron. Soc. 73, 553-576. 1983.

20 B.A. Warren. Bottom water transport through the Southwest Indian Ridge, Deep-Sea Res. 25, 315-321, 1978.

21 C. Tapscott, P. Patriat, R.L. Fisher, J.G. Sclater, H. Hoskins and $B$. Parsons, The Indian Ocean Triple Junction. J. Geophys. Res. 85, 4723-4739, 1980.

22 R. Schlich and P. Patriat, Mise on evidence d'anomalies magnétiques axiales sur la branche ouest de la dorsale médio-indiene, C.R. Acad. Sci. Paris, Sér. D. 272. 700-703. 1971.
23 H.W. Bergh, Sea-floor spreading in the Southwest Indian Ocean, J. Geophys. Res. 76, 6276-6282, 1971.

24 P. Patriat, Ph.D. Thesis, University of Paris 6, 1983.

25 P. Patriat and V. Courtillot, On the stability of triple junctions and its relation to episodicity in spreading. Tectonics, in press.

26 M.E. Chapman, Geoid anomaly over Mid-Ocean Ridges, EOS, 58, 368, 1977.

27 R.L. Parker and D.W. Oldenburg. Thermal model of ocean ridges, Nature Phys. Sci. 242, 137-139, 1973.

28 E.E. Davis and C.R.B. Lister, Fundamentals of ridge crest topography. Earth Planet. Sci. Lett. 21, 405-413, 1974.

29 J.G. Sclater and J. Francheteau. The implications of terrestrial heat now observations on current tectonic and geochemical models of the crust and upper mantle of the Earth, Geophys. J. R. Astron. Soc. 20, 509-542, 1970.

30 B. Parsons and J.G. Sclater, An analysis of the variation of ocean floor bathymetry and heat flow with age, J. Geophys. Res. 82, 803-827, 1977.

31 W.F. Haxby, The mid-ocean ridge geoid anomaly, EOS (Trans. Am. Geophys. Union) 60, 391, 1979.

32 D.T. Sandwell and G. Schubert, Geoid height versus age for symmetric spreading ridges, J. Geophys. Res. 85, 7235-7241, 1980.

33 J.R. Ockendon and D.L. Turcotte, On the gravitational potential and field anomalies due to thin mass layers, Geophys. J. R. Astron. Soc. 48, 479, 1977.

34 General Bathymetric Chart of the Oceans (GEBCO), 5th ed., Canadian Hydrographic Service, Ottowa, Ont., 1982.

35 J.R. Cochran, An analysis of isostasy in the world's oceans, 2. Mid-ocean ridge crests, J. Geophys. Res. 84, 3637-3653, 1979.

36 A.B. Watts, Gravity anomalies over oceanic rifts, in: Continental and Oceanic Rifts, G. Palmason, ed., Am., Geophys. Union, Geodyn. Ser. 8, 99-106, 1982.

37 B.T.R. Lewis, Constraints on the structure of the East Pacific Rise from gravity, J. Geophys. Res. 87, 8491-8500, 1982.

38 D.P. McKenzie and C. Bowin, The relationship between bathymetry and gravity in the Atlantic Ocean, J. Geophys. Res. 81, 1903-1915, 1976. 